Quim. Nova, Vol. 36, No. 7, 1030-1037, 2013

\title{
MÉTODOS PARA ANÁLISES DE HPA E BTEX EM ÁGUAS SUBTERRÂNEAS DE POSTOS DE REVENDA DE COMBUSTÍVEIS: UM ESTUDO DE CASO EM CAMPO GRANDE, MS, BRASIL
}

\author{
Sâmya Soler Gebara, Nilva Ré-Poppi* e André Luiz Carneiro Soares do Nascimento \\ Departamento de Química, Universidade Federal de Mato Grosso de Sul, 79080-190 Campo Grande - MS, Brasil \\ Jorge Luiz Raposo Junior \\ Faculdade de Ciências Exatas e Tecnologia, Universidade Federal da Grande Dourados, 79804-970 Dourados - MS, Brasil
}

Recebido em 11/9/12; aceito em 5/3/13; publicado na web em 6/5/13

\begin{abstract}
METHODS FOR ANALYSIS OF PAH AND BTEX IN GROUNDWATER FROM GAS STATIONS: A CASE STUDY IN CAMPO GRANDE, MS, BRAZIL. Two methods using headspace solid-phase microextraction and gas chromatography-mass spectrometry were developed for the determination of polycyclic aromatic hydrocarbons (PAH) and BTEX. Best results were obtained using $\mathrm{DVB} / \mathrm{CAR} / \mathrm{PDMS}$ fiber, with $10 \mathrm{~min}$ extraction at $25^{\circ} \mathrm{C}$ and 0.15 min desorption at $260{ }^{\circ} \mathrm{C}$ (BTEX), and PDMS/DVB fiber, with 60 min extraction at $90{ }^{\circ} \mathrm{C}, 10 \% \mathrm{NaCl}$ and 5 min desorption at $270{ }^{\circ} \mathrm{C}(\mathrm{PAH})$. LOD intervals were $3 \times 10^{-2}-5 \times 10^{-2} \mu \mathrm{g} \mathrm{L} \mathrm{L}^{-1}$ (BTEX) and $1.6 \times 10^{-3}-1.4 \mu \mathrm{g} \mathrm{L} \mathrm{L}^{-1}(\mathrm{PAH})$. The methods were applied to forty-five groundwater samples from monitoring wells of gas stations and only benzene level exceeded the limit established by Brazilian regulations.
\end{abstract}

Keywords: groundwater; aromatic hydrocarbons; HS-SPME/GC-MS/MS.

\section{INTRODUÇÃO}

No Brasil existem 38.491 postos revendedores de combustíveis automotivos sujeitos ao monitoramento segundo dados de julho de 2012 da Agência Nacional do Petróleo, Gás Natural e Biocombustíveis (ANP). ${ }^{1}$ Com uma média de quatro tanques por posto, estima-se 154.000 tanques subterrâneos em todo o território brasileiro. Muitos destes tanques foram instalados no início da década de 70, e como possuem média de vida útil de 25 anos, supõe-se que eles já estejam comprometidos. ${ }^{2}$

Considera-se que toda instalação e sistemas de armazenamento de derivados de petróleo e outros combustíveis configuram-se como empreendimentos potencialmente poluidores e geradores de acidentes ambientais, e segundo Resolução CONAMA no 273/2000 devem passar por todas as etapas do Licenciamento Ambiental. ${ }^{3} \mathrm{Uma}$ das etapas é a análise química da água subterrânea dos postos de combustíveis para determinar as concentrações de hidrocarbonetos policíclicos aromáticos (HPA) e de benzeno, tolueno, etilbenzeno e xilenos (BTEX), a fim de verificar contaminações por gasolina, diesel e óleo lubrificante. ${ }^{4}$ Órgão como o CONAMA dispõe sobre a classificação e diretrizes ambientais para o enquadramento das águas subterrâneas, bem como os valores máximos permitidos em água para o consumo humano (VMP) para substâncias como os HPA e BTEX. ${ }^{5}$ Os valores máximos permitidos em água para o consumo humano (VMP), conforme Portaria ${ }^{\circ}$ 2914/2011 do Ministério da Saúde e Resolução $\mathrm{n}^{\circ} 396$ do CONAMA, são: $5 \mu \mathrm{g} \mathrm{L^{-1 }}$ de benzeno, $170 \mu \mathrm{g}$ $\mathrm{L}^{-1}$ de tolueno, $200 \mu \mathrm{g} \mathrm{L}^{-1}$ de etilbenzeno e $300 \mu \mathrm{g} \mathrm{L}^{-1}$ de xileno total $(o+m+p) .{ }^{5,6}$ Para HPA a Resolução estabelece VMP de $0,05 \mu \mathrm{g} \mathrm{L}^{-1} \mathrm{de}$ cada um dos seguintes HPA: benzo[b]fluoranteno, benzo[a]antraceno, benzo[k]fluoranteno, benzo[a]pireno, criseno, dibenzo[a,h]antraceno e indeno[1,2,3-cd]pireno.

O município de Campo Grande, MS, não dispõe de um programa bem estruturado de monitoramento da qualidade das águas subterrâneas em postos de revenda de combustíveis automotores, e por isso torna-se de extrema relevância a determinação destas substâncias nestes locais.
A técnica mais utilizada para determinação de BTEX e HPA em água é a cromatografia a gás, no entanto esta necessita de uma etapa de extração e pré-concentração destes analitos para que sejam alcançados os baixos limites de determinação exigidos e para eliminar os constituintes que possam danificar o sistema cromatográfico. Diversas técnicas de extração e pré-concentração de BTEX têm sido reportadas na literatura, como a extração headspace (HS), purga e trapeamento (purge and trap), microextração em gota única (single drop microextration: SDME), microextração em fase líquida com fibra oca (hollow fiber supported liquid-phase microextraction: HF-LPME), extração com membranas com uma interface sorvente (flat-sheet membrane extraction with a sorbent interface: MESI) e microextração em fase sólida (solid phase microextraction: SPME). ${ }^{7-17}$

Purge and trap é a técnica utilizada na extração de BTEX no método oficial EPA 524.2 (PT-GC/MS) e os limites encontrados são similares aqueles determinados por microextração em fase sólida..$^{9,18}$

A determinação de BTEX em água por GC-FID com as técnicas de extração, HS estático e HS-SPME, foi estudada por Menéndez e colaboradores. ${ }^{8}$ As duas técnicas revelaram-se suficientemente exatas e precisas $(\mathrm{CV} \approx 4 \%$ ) com limites de detecção para HS de 1-2 $\mu \mathrm{g}$ $\mathrm{L}^{-1}$ e para HS-SPME de 0,2-1 $\mu \mathrm{g} \mathrm{L}{ }^{-1}$, sendo HS-SPME mais sensível, seletiva e relativamente rápida. ${ }^{8} \mathrm{O}$ método de extração HS-SPME e análise GC-MS mostrou melhores resultados para os parâmetros de validação no estudo comparativo com a técnica de headspace. ${ }^{7}$ Para as técnicas SDME e HF-LPME em análise GC-FID foram observados limites de detecção para BTEX em água entre $0,8-7 \mu \mathrm{g} \mathrm{L}^{-1} \mathrm{e}$ 2,7-4,0 $\mu \mathrm{g} \mathrm{L}^{-1} .^{12-14}$

Para a determinação de HPA em água os procedimentos de extração líquido-liquido, extração em fase sólida (solid-phase extraction: SPE), extração sortiva em barra de agitação (stir bar sorptive extraction: SBSE), extração com solvente assistida por membranas (membrane assisted solvent extraction: MASE) e microextração em fase sólida têm sido bastante utilizados. ${ }^{10,19-28}$ Limites de detecção (LD) equivalentes foram relatados para métodos de SPE, SBSE acoplada à adsorção térmica (TD) em sistema GC-MS, MASE acoplada ao grande volume de injeção (LVI) em vaporizador com temperatura programada (PTV). ${ }^{20,25,26}$

Métodos convencionais como a extração líquido-líquido (LLE) e a 
extração em fase sólida (SPE) requerem o uso de solventes orgânicos e envolvem muitas vezes operações demoradas, complicadas e de elevado custo. Estes têm sido gradualmente substituídos por métodos analíticos revisados e melhorados com as novas tecnologias, com a finalidade de minimizar o uso de solventes orgânicos e permitir a automação da análise para melhorar a robustez dos métodos. ${ }^{25}$ Neste contexto, a MASE permite a redução da quantidade de solvente orgânico para volumes típicos entre 500-1000 $\mu \mathrm{L}$ e a SBSE e a SPME não utilizam solventes orgânicos.

SPME e SBSE apresentam uma série de vantagens como o uso de pequeno volume de amostra, aplicáveis no modo direto e headspace e permitem a automação das análises. Os analitos, em ambas as técnicas, podem ser extraídos da fase polimérica por dessorção térmica. A dessorção térmica dos analitos da fibra de SPME ocorre dentro do injetor do cromatógrafo a gás, não necessita de equipamento específico e dispendioso e integra em um único sistema, a extração, concentração e introdução da amostra no sistema cromatográfico. Para a dessorção térmica em SBSE é necessário o uso de um sistema para ser acoplado a cromatógrafo a gás equipado com injetor de temperatura programada. Neste sistema, a barra de SBSE é introduzida em um tubo de vidro (interface) e encaminhada para o injetor onde ocorre à rápida dessorção térmica e na sequencia a reconcentração criogênica dos analitos. Após, inicia-se o aumento gradual da temperatura e os analitos são transportados à coluna analítica para a separação cromatográfica. ${ }^{29}$

O presente trabalho teve como objetivo desenvolver e validar dois métodos alternativos, não simultâneos, para determinação de BTEX e HPA em água usando HS-SPME/GC-MS/MS. Amostras de água subterrânea foram coletadas de postos de combustíveis em Campo Grande, capital do estado de Mato Grosso do Sul, nas quais HPA e BTEX foram extraídos e analisados empregando os métodos validados.

\section{PARTE EXPERIMENTAL}

\section{Amostragem}

O município de Campo Grande possui aproximadamente 165 postos de revenda de combustíveis automotivos. Na Região Urbana Central encontram-se instalados, em média, 49 postos, ou seja, 32,2 $\%$ do total ${ }^{4}$ e como em outras capitais do país estão localizados na parte mais antiga da cidade. A idade e má conservação das instalações podem facilitar a ocorrência de danos ao meio ambiente. Desta forma um total de 15 postos da região central foi avaliado para a determinação de BTEX e HPA. Cada posto de combustível possui diversos poços de monitoramento, variando entre 1 e 12 poços. Cabe ressaltar que tanto os proprietários quanto o órgão fiscalizador dos estabelecimentos não possuem dados referentes ao histórico do lugar, a profundidade do poço e tão pouco ao fluxo e sentido do lençol freático. Para uma amostragem mais representativa, optou-se por coletar água dos poços que formavam um triângulo no perímetro do posto, ou seja, foram investigados três poços por estabelecimento, totalizando 45 amostras. A profundidade dos poços foi medida com um medidor de nível e foi coletado um litro de água em frascos de vidro âmbar de cada poço conforme Norma 6410/88 da CETESB.

\section{Padrões, reagentes e equipamentos}

Os padrões de HPA foram adquiridos da AccuStandard (USA) em solução de diclorometano/benzeno (1:1) (Z-014G, lote B8020171), concentração de 2,0 $\mathrm{mg} \mathrm{mL}^{-1}$ de naftaleno (Naf), acenaftileno (Aci), acenafteno (Ace), fluoreno (Flu), fenantreno (Fen), antraceno (Ant), fluoranteno (Flt), pireno (Pir), benzo[a]antraceno (BaA), criseno (Cri), benzo[b]fluoranteno $(\mathrm{BbF})$, benzo[a]pireno $(\mathrm{BaP})$, benzo[k] fluoranteno (BkF), indeno[1,2,3-cd]pireno (Ind), dibenzo[a,h]antraceno (DBahA) e benzo[g,h.i]perileno (BghiP).

O padrão misto dos BTEX foi adquirido da SUPELCO (Sigma Aldrich $^{\circledR}$, USA) em ampola de 1,0 mL (47993-SUPELCO, USA), lote LB58030 contendo hidrocarbonetos monocíclicos aromáticos em solução de metanol, com concentração de $2000 \mu \mathrm{g} \mathrm{mL}^{-1}$ das seguintes substâncias: benzeno, metil-benzeno (tolueno), etil benzeno, 1,2-dimetil benzeno ( $o$-xileno), 1,3-dimetil benzeno ( $m$-xileno) e 1,4-dimetil benzeno ( $p$-xileno).

Frascos de vidro de $20 \mathrm{~mL}(75,50 \times 22,50 \mathrm{~mm})$, tampa de rosca de aço inox (diâmetro interno: $18 \mathrm{~mm}$, altura: $11 \mathrm{~mm}$ ) e septo de PTFE/silicone (espessura: 1,3 mm).

Metanol (SupraSolv) adquirido da Merck ${ }^{\circledR}$ (Darmstadt, Alemanha) foi o solvente utilizado para o preparo das soluções. Balança analítica, marca SHIMADZU, modelo AY 220, com capacidade de 220 g e leitura mínima de $0,1 \mathrm{mg}$ e $80 \mathrm{~mm}$ de diâmetro de prato.

Fibras DVB/CAR/PDMS 50/30 $\mu \mathrm{m}$, PDMS $7 \mu \mathrm{m}$, PDMS 100 $\mu \mathrm{m}, \mathrm{CAR} / \mathrm{PDMS} 85 \mu \mathrm{m}$ e PDMS/DVB $65 \mu \mathrm{m}$ foram adquiridas da Supelco (Sigma Aldrich ${ }^{\circledR}$, USA), e as fibras NiTi-ZrO ${ }_{2} 1,3 \mu \mathrm{m}$, NiTi$\mathrm{ZrO}_{2}$-PDMS $35 \mu \mathrm{m}$ (sol-gel) foram cedida pelo professor Dr. Eduardo Carasek da Universidade Federal de Santa Catarina.

Banho termostatizado redondo com agitação magnética marca Fisatom, modelo 555-2, temperatura controlada por termostato capilar de $50-120^{\circ} \mathrm{C}\left( \pm 2{ }^{\circ} \mathrm{C}\right)$ e controle eletrônico de rotação de 150-1200 rpm.

Ácido clorídrico 37\% (PA) e hidróxido de sódio em micro pérolas (97\% pureza, Dinâmica, Brasil) foram usados no ajuste do $\mathrm{pH}$, cloreto de sódio (99,9\% pureza, Dinâmica, Brasil) foi usado no controle da força iônica.

As análises foram realizadas usando um cromatógrafo a gás GC3900 acoplado a um espectrômetro de massas Saturn 2100 T/MS/MS da Varian (Agilent Technologies, Santa Clara, CA, USA), equipado com injetor modelo 1177 (split-splitless), liner com diâmetro interno de 0,75 mm para SPME e analisador de massas do tipo íon trap. O Software Saturn GC/MS 5.52 e biblioteca NIST 2.0 foram utilizados para controle do instrumento e tratamento de dados, respectivamente. Para a separação cromatográfica foi empregada uma coluna capilar de sílica fundida com fase estacionária de polidimetilsiloxano com 5 $\%$ de fenila (VF-5 ms, ValcoBond) medindo $30 \mathrm{~m}$ de comprimento, $0,25 \mathrm{~mm}$ de d.i. e $0,25 \mu \mathrm{m}$ de espessura do filme. $\mathrm{O}$ gás de arraste utilizado foi hélio (99,999\% de pureza, White Martins, Brasil) em fluxo constante de $1,0 \mathrm{~mL} \mathrm{~min}^{-1}$.

\section{Preparo das soluções}

A solução estoque contendo $200 \mathrm{mg} \mathrm{L}^{-1}$ de cada um dos $16 \mathrm{HPA}$ foi preparada em metanol pela diluição de $1,0 \mathrm{~mL}$ da solução de 2,0 $\mathrm{mg} \mathrm{mL}^{-1}$ em balão volumétrico de $10,0 \mathrm{~mL}$. Soluções intermediárias foram preparadas a partir de alíquotas dessa solução estoque também em metanol. Os frascos foram bem vedados, protegidos da luz e armazenados a $-4{ }^{\circ} \mathrm{C}$. As soluções de trabalho foram preparadas em água ultrapura obtida em sistema Milli-Q (Millipore da Bedford, MA, USA) no dia da análise. Estas foram preparadas pela transferência de alíquotas da solução estoque ou intermediária dependendo da concentração da solução de trabalho, para um balão volumétrico de $50 \mathrm{~mL}$ e o volume ajustado com solução $10 \%$ de $\mathrm{NaCl}$. Uma alíquota de $10 \mathrm{~mL}$ da solução trabalho foi transferida para o frasco de $20 \mathrm{~mL}$ para inicio do procedimento de extração por meio da SPME.

A solução estoque de BTEX na concentração de $40 \mathrm{mg} \mathrm{L}^{-1}$ foi preparada por diluição de 1,0 mL em metanol da solução de 2000 $\mu \mathrm{g} \mathrm{mL}^{-1}$ para um volume final de $50 \mathrm{~mL}$. As soluções intermediárias e de trabalho de BTEX foram preparadas e armazenadas de forma similar as de HPA. Porém, no procedimento de extração de BTEX 
não foi utilizada solução salina, de forma que as soluções de trabalho foram preparadas apenas em água ultrapura.

\section{Desenvolvimento do método HS-SPME/GC-MS/MS para BTEX em água}

A temperatura inicial da coluna foi de $40{ }^{\circ} \mathrm{C}$ por $3 \mathrm{~min}$, e a seguir foi elevada de 40 a $60{ }^{\circ} \mathrm{C}$ com aquecimento de $10^{\circ} \mathrm{C} \mathrm{min}{ }^{-1}$, permanecendo nessa temperatura por $4 \mathrm{~min}$. A temperatura do injetor foi de $260{ }^{\circ} \mathrm{C}$ a da linha de transferência foi de $200{ }^{\circ} \mathrm{C}$. No espectrômetro de massas as temperaturas foram de $200{ }^{\circ} \mathrm{C}$ na armadilha de íons e de $70{ }^{\circ} \mathrm{C}$ no manifold.

Os parâmetros utilizados para a análise por espectrometria de massas em série (MS/MS) foram estabelecidos, após estudo, onde se selecionou como íon precursor o íon molecular do hidrocarboneto monoaromático para a fragmentação com as energias de excitação estabelecidas no modo ressonante $(0,1-1 \mathrm{~V})$ e não ressonante (10$100 \mathrm{~V})$. Os íons precursores, as energias de excitação e os íons de quantificação estabelecidos na análise por $M S / M S$ são mostrados na Tabela 1. Nesta análise fixou-se como corrente de emissão: $20 \mu \mathrm{A}$; multiplicador de elétrons: $0 \mathrm{~V}$; contagem de íons: 10000; velocidade: 0,35 s por varredura; tempo de isolamento: $5 \mathrm{msec}$; amplitude de banda larga: $30 \mathrm{~V}$ e amplitude de ejeção: $20 \mathrm{~V}$.

O recobrimento DVB/CAR/PDMS 50/30 $\mu \mathrm{m}$ foi selecionado para se efetuar a extração de BTEX em água, por apresentar melhor desempenho analítico em relação às fibras CAR/PDMS $85 \mu \mathrm{m}, \mathrm{NiTi}-\mathrm{ZrO}_{2}$ $1,35 \mu \mathrm{m}$ e NiTi- $\mathrm{ZrO}_{2} 35 \mu \mathrm{m}$ utilizadas em ensaios de laboratório para seleção do recobrimento. Isto foi provavelmente devido à presença de carboxen (carvão activado), o qual é adequado para a absorção de moléculas pequenas (volátil), resultados semelhantes aos obtidos neste trabalho são encontrado na literatura..$^{30}$

A extração foi efetuada no modo headspace em frasco de vidro de $20 \mathrm{~mL}$ com tampa de rosca em aço inoxidável, septo de PTFE/ silicone de $11 \mathrm{~mm}$ e Holder manual. Para alcançar maior eficiência de extração alguns parâmetros foram avaliados: temperatura de extração, força iônica, $\mathrm{pH}$, tempo de extração, tempo de dessorção e formas de agitação da amostra. Os estudos para determiná-los foram realizados empregando-se $10 \mathrm{~mL}$ de solução padrão contendo BTEX em concentração de $100 \mu \mathrm{g} \mathrm{L}^{-1}$. Todas as análises foram feitas em triplicata.

O injetor após otimização da temperatura e do tempo de dessorção dos analitos da fibra foi mantido a $260^{\circ} \mathrm{C}$, sem divisão de fluxo (modo splitless) por 0,15 min e, após esse tempo, com divisão de fluxo (split) na razão de 1:50. A fibra ficou inserida no injetor durante toda a corrida cromatográfica para limpeza e quando necessário efetuou-se uma corrida cromatográfica para limpeza da fibra entre as avaliações. Um branco da fibra foi obtido todos os dias antes do inicio das análises.

\section{Desenvolvimento do método HS-SPME/GC-MS/MS para análise de HPA em água}

As temperaturas do injetor e da linha de transferência foram mantidas a $270{ }^{\circ} \mathrm{C}$. A programação da temperatura do forno foi a seguinte: $100{ }^{\circ} \mathrm{C}$ por $1,0 \mathrm{~min}$, taxa de aquecimento de $10{ }^{\circ} \mathrm{C} \mathrm{min}{ }^{-1}$ até $200{ }^{\circ} \mathrm{C}$ e de $7{ }^{\circ} \mathrm{C} \mathrm{min}^{-1}$ para elevar de 200 a $250{ }^{\circ} \mathrm{C}$, isoterma 6,0 min, finalmente um aquecimento de $20^{\circ} \mathrm{C} \mathrm{min}^{-1}$ até $300{ }^{\circ} \mathrm{C}$ e isoterma 5,0 min. As temperaturas no espectrômetro de massas foram fixadas a $200{ }^{\circ} \mathrm{C}$ na armadilha de íons e de $70{ }^{\circ} \mathrm{C}$ no manifold.

Os espectros de massas dos HPA foram obtidos em análise por GC-MS de $1 \mu \mathrm{L}$ da solução padrão de $10 \mathrm{mg} \mathrm{L}^{-1}$, com divisão de fluxo na razão de 1:10 e aquisição no modo varredura de íons de 60-320 m/z.

Para o desenvolvimento do modo de análise por espectrometria de massas em série selecionou-se o íon $(\mathrm{m} / \mathrm{z})$ de maior intensidade do espectro de massas do HPA para a fragmentação com as energias de excitação estabelecidas, modo ressonante $(0,1-1 \mathrm{~V})$ e não ressonante (10-100 V). Os íons precursores, as energias de excitação e os íons de quantificação do método MS/MS são mostrados na Tabela 1. Para

Tabela 1. Parâmetros de aquisição do GC-MS/MS nos métodos de análises de BTEX e HPA

\begin{tabular}{|c|c|c|c|c|}
\hline Hidrocarboneto & Tempo de retenção (min) & Íon precursor $(m / z)$ & Íon de quantificação $(m / z)$ & Energia de excitação (V) \\
\hline Benzeno & 2,842 & 78 & $77 ; 78$ & 20 \\
\hline Tolueno & 4,563 & 91 & $91 ; 92$ & 0 \\
\hline Etilbenzeno & 6,845 & 91 & $91 ; 106$ & 0 \\
\hline$m$-p-xileno & 7,162 & 91 & $91 ; 106$ & 0 \\
\hline$o$-xileno & 7,967 & 91 & $91 ; 106$ & 0 \\
\hline Naf & 4,942 & 128 & 128 & 0,20 \\
\hline Aci & 8,158 & 152 & 150 & 0,80 \\
\hline Ace & 8,559 & 153 & $151 ; 152 ; 154$ & 1,00 \\
\hline Flu & 9,743 & 165 & $115 ; 139 ; 163$ & 0,90 \\
\hline Fen & 12,016 & 178 & 178 & 0,10 \\
\hline Ant & 12,151 & 178 & 178 & 0,10 \\
\hline Flt & 15,914 & 202 & 202 & 0,20 \\
\hline Pir & 19,888 & 202 & 202 & 0,20 \\
\hline $\mathrm{BaA}$ & 20,022 & 228 & 228 & 0,20 \\
\hline Cri & 25,349 & 228 & 228 & 0,20 \\
\hline $\mathrm{BbF}$ & 25,452 & 252 & 252 & 0,20 \\
\hline $\mathrm{BkF}$ & 26,384 & 252 & 252 & 0,20 \\
\hline $\mathrm{BaF}$ & 29,539 & 252 & 252 & 0,20 \\
\hline Ind+DBahA & 29,649 & 276 & 276 & 0,20 \\
\hline BghiP & 30,351 & 276 & 276 & 0,20 \\
\hline
\end{tabular}


as análise MS/MS estabeleceu-se para corrente de emissão: $50 \mu \mathrm{A}$; multiplicador de elétrons: $+200 \mathrm{~V}$; contagem de íons: 5000; velocidade: 0,35 s por varredura; tempo de isolamento: $5 \mathrm{msec}$; amplitude de banda larga: $30 \mathrm{~V}$ e amplitude de ejeção: $20 \mathrm{~V}$.

As fibras PDMS $7 \mu \mathrm{m}$, PDMS $100 \mu \mathrm{m}$ e PDMS/DVB $65 \mu \mathrm{m}$ foram testadas para avaliar a eficiência na extração dos HPA. Os ensaios foram realizados usando $10 \mathrm{~mL}$ da solução padrão de 10 $\mu \mathrm{g} \mathrm{\textrm {L } ^ { - 1 }}$ de HPA em frasco de $20 \mathrm{~mL}$ com 2,0 g de $\mathrm{NaCl}$. Efetuou-se a extração no modo headspace mantendo-se as seguintes condições experimentais: tempo de extração de 60 min, tempo de dessorção de 5 min, temperatura de extração de $80^{\circ} \mathrm{C}$, sob agitação e em pH neutro. A Figura 1 mostra o valor das áreas obtidas para os HPA extraídos pelas fibras. A fibra PDMS $100 \mu \mathrm{m}$ apresentou melhor absorção para os HPA de massa molar mais elevada. No entanto, a fibra PDMS/DVB $65 \mu \mathrm{m}$ extraiu melhor um número maior de analitos.

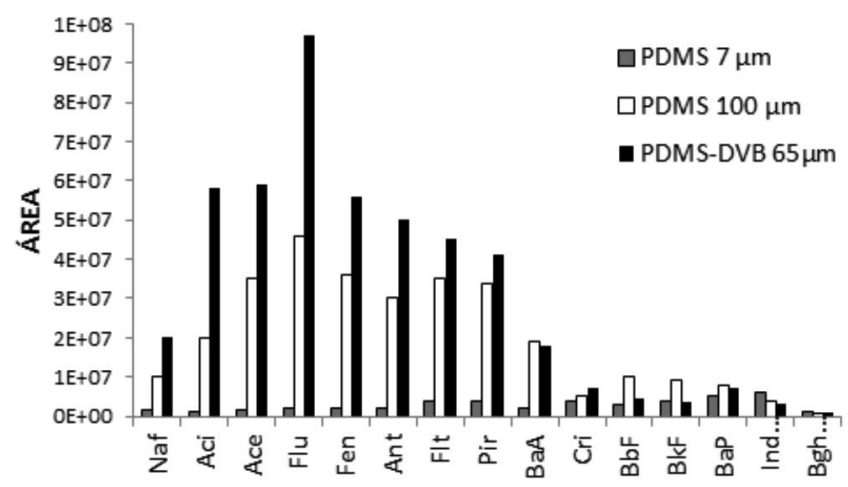

Figura 1. Estudo comparativo de três diferentes fibras utilizando uma solução padrão contendo $10 \mu \mathrm{g} \mathrm{L}^{-1}$ de cada HPA empregando a HS-SPME/GC-MS/MS

Usando a fibra PDMS/DVB $65 \mu \mathrm{m}$ foram realizados ensaios para definição da temperatura de extração, força iônica e pH do meio, tempos de extração e de dessorção. Estes foram realizados empregando uma solução contendo $10 \mu \mathrm{g} \mathrm{L}^{-1}$ de cada um dos $16 \mathrm{HPA}$. Todas as análises foram feitas em triplicatas.

\section{Validação dos métodos HS-SPME/GC-MS/MS}

Os parâmetros analíticos investigados na validação dos métodos foram seletividade, linearidade, sensibilidade (limites de detecção e quantificação), precisão e exatidão. Para determinar a seletividade efetuou-se a comparação entre o cromatograma da matriz (água subterrânea isenta dos analitos) com o cromatograma da matriz enriquecida com padrões. Os limites de detecção (LD) e quantificação (LQ) foram calculados baseados na razão sinal ruído dos picos nas análises de soluções padrões por HS-SPME/GC-MS/MS, assumindo a razão 10:1 para $L Q$ e 3:1 para $L D$.

Para obter as curvas de calibração analisaram-se entre 5 e 6 concentrações diferentes do padrão, em triplicata, por meio da HS-SPME/ GC-MS/MS. As curvas de calibração foram obtidas para BTEX com concentrações de 0,5-64 $\mu \mathrm{g} \mathrm{L}^{-1}$. Para os HPA as curvas de calibração foram construídas com valores de concentrações de 0,02-0,12 $\mu \mathrm{g} \mathrm{L}^{-1}$ para Naf, Aci, Ace, Flu, Fen, Ant, Flt, Pir, BaA+Cri, BbF+BkF e de 1-10 $\mu \mathrm{g} \mathrm{L}^{-1}$ para BaP, Ind+DBahA e BghiP.

A exatidão e precisão do método foram investigados por meio de ensaios de recuperação relativa e coeficientes de variações das replicatas $(n=3)$, respectivamente. Os testes de recuperação relativa foram feitos adicionando-se os analitos às amostras reais (água subterrânea) em dois níveis de concentração para cada analito. Os níveis de concentração para BTEX foram: 1 e $16 \mu \mathrm{g} \mathrm{L}^{-1}$ e para HPA: 0,05 e $0,11 \mu \mathrm{g} \mathrm{L}^{-1}$ (curva analítica de $0,02-0,12 \mu \mathrm{g} \mathrm{L}^{-1}$ ), exceto para
BaP, Ind+DBahA e BghiP que foram de 3 e $9 \mu \mathrm{g} \mathrm{L}^{-1}$ (curva analítica $\left.1-10 \mu \mathrm{g} \mathrm{L}^{-1}\right)$.

Determinação de BTEX e HPA nas amostras de água de postos de revenda de combustível

Os métodos HS-SPME/GC-MS/MS validados foram aplicados às amostras de água para avaliar as concentrações de HPA e BTEX.

A amostra foi deixada por $2 \mathrm{~h}$ em uma sala termostatizada a 25 ${ }^{\circ} \mathrm{C}$. Após, transferiu-se uma alíquota de $10 \mathrm{~mL}$ da amostra para o frasco onde se efetuou a extração de BTEX com a fibra DVB/CAR/ PDMS 50/30 $\mu \mathrm{m}$, expondo-a ao headpace da amostra por $10 \mathrm{~min}$. A dessorção dos analitos ocorreu no injetor do cromatógrafo a uma temperatura de $260^{\circ} \mathrm{C}$ por $0,15 \mathrm{~min}$.

Para determinação de HPA foram transferidos para o frasco 10 $\mathrm{mL}$ da amostra e $1 \mathrm{~g}$ de $\mathrm{NaCl}$, em seguida a amostra foi aquecida em banho-maria a $90^{\circ} \mathrm{C}$. A extração foi efetuada no headspace com agitação da amostra, empregando a fibra PDMS/DVB $(65 \mu \mathrm{m})$ por $60 \mathrm{~min}$.

Todas as análises foram feitas em triplicata. As amostras cujas substâncias apresentaram teores acima da faixa linear de calibração estabelecida foram diluídas com água ultrapura. A concentração do analito foi calculada usando a equação da reta obtida na calibração analítica.

\section{Análise de agrupamento hierárquico (Hierarchical Cluster Analysis - HCA)}

Os dados foram processados utilizando o software MINITAB 15 para Windows ${ }^{\circledR}$ para identificar o nível de similaridade entre as amostras. A matriz foi construída com os valores obtidos de concentração para BTEX e HPA. Estes foram normalizados como forma de pré-processamento antes da análise. $\mathrm{Na}$ análise de agrupamento utilizou-se o método de ligação média entre os agrupamentos e como métrica a distância euclidiana.

\section{RESULTADOS E DISCUSSÃO}

\section{Método HS-SPME/GC-MS/MS para determinação de BTEX}

A Figura 2 mostra os gráficos obtidos com os resultados dos experimentos realizados para definição das temperaturas de extração e dessorção, do tempo de extração e força iônica. Observou-se melhor eficiência de extração de BTEX para o tempo de $10 \mathrm{~min}$ a $25{ }^{\circ} \mathrm{C}$, e tempo de dessorção de 0,15 min a uma temperatura de $260{ }^{\circ} \mathrm{C}$. Os experimentos realizados com $0,10,20$ e $30 \%(\mathrm{~m} / \mathrm{v}) \mathrm{de}$ cloreto de sódio na amostra evidenciaram maior eficiência para a extração sem adição de $\mathrm{NaCl}$. A agitação magnética ou ultrassônica da amostra não evidenciou maior eficiência de extração. Os seguintes parâmetros foram fixados para análise de BTEX nas amostras de água de poço de posto de combustíveis: tempo de extração de 10 min, temperatura de extração de $25^{\circ} \mathrm{C}$, temperatura de dessorção de $260^{\circ} \mathrm{C}$, tempo de dessorção de 0,15 min sem adição de sal e $\mathrm{pH} 6$.

O método de análise apresentou-se seletivo para BTEX. A Tabela 2 mostra a faixa de linearidade investigada para os analitos $(n=5)$, os coeficientes de determinação $\left(\mathrm{r}^{2}\right)$, LD e LQ. Foram observados valores de $r^{2}$ entre 0,9908 e 0,9956. Obtiveram-se limites de detecção do método para benzeno e tolueno de $5,0 \times 10^{-2} \mu \mathrm{g} \mathrm{L}^{-1} \mathrm{e}$ para etilbenzeno e xileno de $3,0 \times 10^{-2} \mu \mathrm{g} \mathrm{L} \mathrm{L}^{-1}$. Os limites de quantificação obtidos situaram se no intervalo de $1,0 \times 10^{-1}-1,5 \times 10^{-1} \mu \mathrm{g} \mathrm{L} \mathrm{L}^{-1}$. Os valores de recuperação relativa situaram-se entre 82,4 e $113,5 \%$ com coeficientes de variações entre 7,9 e 17,3\% para concentrações adicionadas de 1 e $16 \mu \mathrm{g} \mathrm{L} \mathrm{L}^{-1}$. 

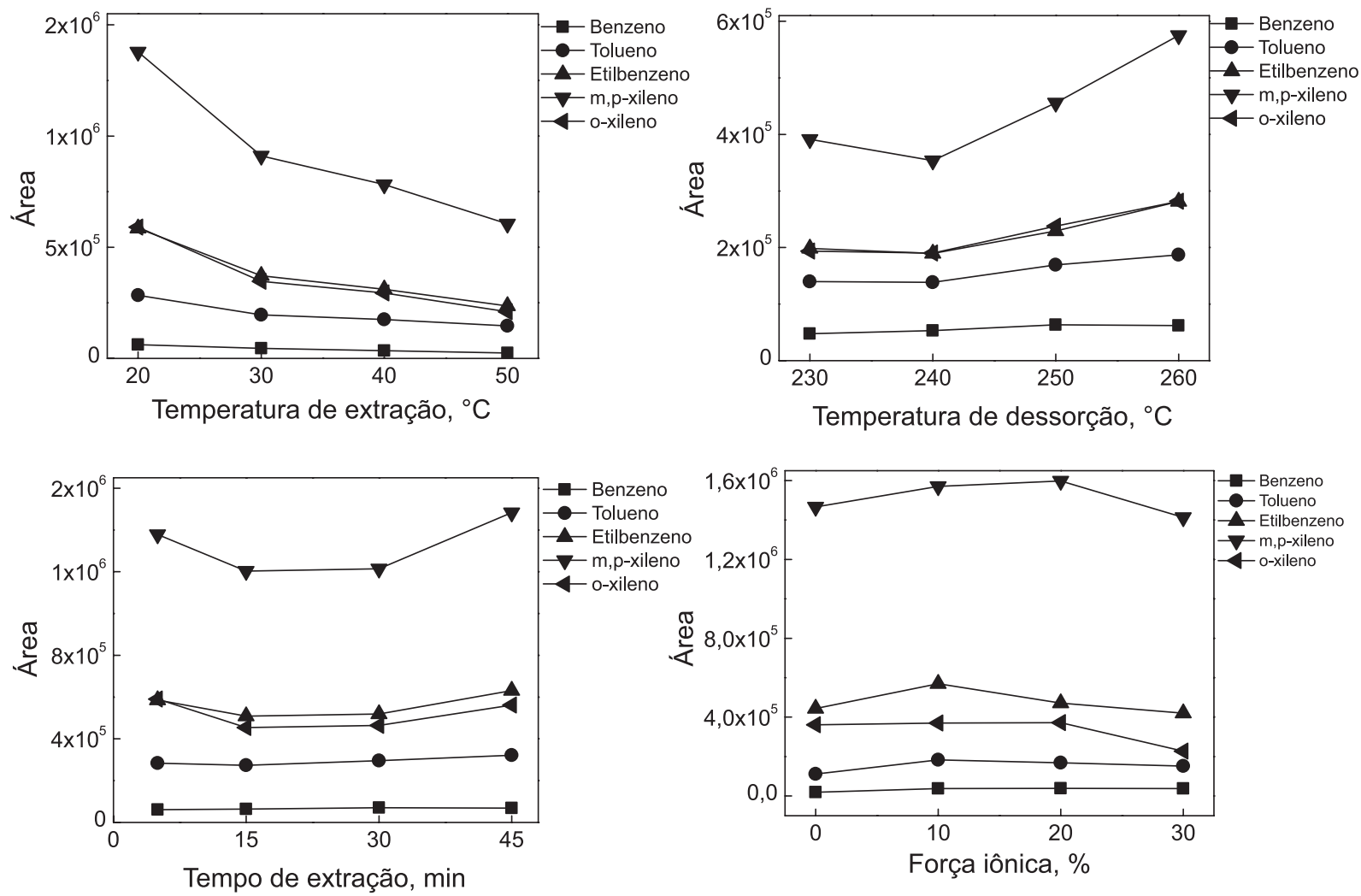

Figura 2. Influência dos parâmetros temperatura de adsorção, temperatura de extração, tempo de extração e força iônica na análise de BTEX empregando a $H S-S P M E / G C-M S / M S$ (fibra DVB/CAR/PDMS 50/30 $\mu \mathrm{m}$ )

Tabela 2. Faixa linear de trabalho e limites de detecção e quantificação

\begin{tabular}{|c|c|c|c|c|c|}
\hline Hidrocarboneto & Faixa de trabalho $\left(\mu \mathrm{g} \mathrm{L}^{-1}\right)$ & $\mathrm{r}^{2}$ & Equação da reta* & $\mathrm{LD}\left(\mu \mathrm{g} \mathrm{L}^{-1}\right)$ & $\mathrm{LQ}\left(\mu \mathrm{g} \mathrm{L}^{-1}\right)$ \\
\hline Benzeno & $0,50-64$ & 0,9936 & $y=38,0160 x+64,9064$ & $5,0 \times 10^{-2}$ & $1,5 \times 10^{-1}$ \\
\hline Tolueno & $0,50-64$ & 0,9830 & $y=448,031 x+2381,21$ & $5,0 \times 10^{-2}$ & $1,5 \times 10^{-1}$ \\
\hline Etilbenzeno & $0,50-64$ & 0,9914 & $y=395,537 x+1154,09$ & $3,0 \times 10^{-2}$ & $1,5 \times 10^{-1}$ \\
\hline$m$-p-xileno & $0,50-64$ & 0,9908 & $y=1608,70 x+3564,13$ & $3,0 \times 10^{-2}$ & $1,0 \times 10^{-1}$ \\
\hline$o$-xileno & $0,50-64$ & 0,9956 & $y=1180,66 x+2640,01$ & $3,0 \times 10^{-2}$ & $1,0 \times 10^{-1}$ \\
\hline $\mathrm{Naf}$ & $0,02-0,12$ & 0,9994 & $y=4429,32 x+16535,3$ & $3,5 \times 10^{-3}$ & $1,1 \times 10^{-2}$ \\
\hline Aci & $0,02-0,12$ & 0,9962 & $y=9726,44 x+12961,3$ & $8,6 \times 10^{-3}$ & $2,6 \times 10^{-2}$ \\
\hline Ace & $0,02-0,12$ & 0,9996 & $y=8876,59 x+142492$ & $2,8 \times 10^{-3}$ & $8,5 \times 10^{-3}$ \\
\hline Flu & $0,02-0,12$ & 0,9986 & $y=12988,1 x+118253$ & $4,6 \times 10^{-3}$ & $1,4 \times 10^{-2}$ \\
\hline Fen & $0,02-0,12$ & 0,9996 & $y=10665,6 x+86172,7$ & $4,6 \times 10^{-3}$ & $1,4 \times 10^{-2}$ \\
\hline Ant & $0,02-0,12$ & 0,994 & $\mathrm{y}=5832,32 \mathrm{x}+126905$ & $4,6 \times 10^{-3}$ & $1,4 \times 10^{-2}$ \\
\hline Flt & $0,02-0,12$ & 0,9982 & $y=9244,97 x+24931,2$ & $5,8 \times 10^{-3}$ & $1,8 \times 10^{-2}$ \\
\hline Pir & $0,02-0,12$ & 0,9998 & $y=6089,24 x+27297,0$ & $1,6 \times 10^{-3}$ & $5,0 \times 10^{-3}$ \\
\hline $\mathrm{BaA}+\mathrm{Cri}$ & $0,02-0,12$ & 0,9995 & $y=5120,18 x-4265,24$ & $4,5 \times 10^{-3}$ & $1,4 \times 10^{-2}$ \\
\hline $\mathrm{BbF}+\mathrm{BkF}$ & $0,02-0,12$ & 0,9980 & $y=2425,13 x-41265,8$ & $6,2 \times 10^{-3}$ & $1,9 \times 10^{-2}$ \\
\hline $\mathrm{BaP}$ & $1-10$ & 0,9972 & $y=750908 x+156171$ & $7,0 \times 10^{-1}$ & 2,0 \\
\hline Ind+DBahA & $1-10$ & 0,9976 & $y=109937 x+21203,1$ & $6,0 \times 10^{-1}$ & 1,9 \\
\hline BghiP & $1-10$ & 0,9878 & $y=4409,20 x+1921,40$ & 1,4 & 2,9 \\
\hline
\end{tabular}

$\mathrm{r}^{2}$ =coeficiente de determinação; *equação da reta para curva analítica (n=5-6).

\section{Método HS-SPME/GC-MS/MS para determinação de HPA}

Os parâmetros fixados após investigação para obter melhor eficiência de extração com a fibra PDMS/DVB $65 \mu \mathrm{m}$ foram: temperatura de extração de $90^{\circ} \mathrm{C}$, tempo de extração de 60 min em banho-Maria com agitação magnética, temperatura de dessorção de $270{ }^{\circ} \mathrm{C}$, tempo de dessorção de 5 min e $10 \%$ de $\mathrm{NaCl}$. Para as análises o injetor foi mantido a $270{ }^{\circ} \mathrm{C}$, sem divisão de fluxo por $5 \mathrm{~min}$ e, após esse tempo, 
com divisão de fluxo nas razões de 1:50 por 8 min e de 1:30 até o término da análise. A fibra ficou inserida no injetor durante toda a corrida cromatográfica para limpeza.

A matriz (água subterrânea) não apresentou picos interferentes no tempo de retenção dos HPA, conferindo seletividade ao método desenvolvido. A Tabela 2 mostra a faixa linear de trabalho, equação da reta $(n=6), r^{2}, L D$ e LQ. Foi observada linearidade com coeficiente de determinação $\left(\mathrm{r}^{2}\right) \geq 0,9972$. Os limites de quantificação ficaram entre 5,0 x $10^{-3}$ e 2,6 x $10^{-3} \mu \mathrm{g} \mathrm{L}^{-1}$, exceto para BaP, Ind+DBahA e BghiP que situaram-se entre 1,9 e $2,9 \mu \mathrm{g} \mathrm{L}^{-1}$. Os valores de recuperação relativa ficaram entre 80,6 e $118,9 \%$, com coeficientes de variações percentuais (CV) entre $3,4 \%$ e $19,8 \%$.

Os limites de detecção do método HS-SPME encontrados neste estudo situaram-se entre $1,6 \times 10^{-3}$ e $6,2 \times 10^{-3} \mu \mathrm{g} \mathrm{L}^{-1}$, exceto para $\mathrm{BaP}$, Ind+DBahA e BghiP (Tabela 2). Utilizando uma fibra de PDMS 30 $\mu \mathrm{m}$ em extração direta a $60{ }^{\circ} \mathrm{C}$ foram determinados limites de detecção situados entre $6 \times 10^{-2}$ e $5 \times 10^{-1} \cdot{ }^{27}$ Os resultados obtidos neste trabalho quando comparados ao da literatura ${ }^{27}$ evidenciaram que a extração headspace foi mais sensível que a extração direta para um maior número dos HPA estudados, os que possuem 2, 3 e 4 anéis aromáticos. O procedimento de extração por imersão da fibra em solução é mais eficiente que a extração por headspace para os HPA que possuem menor pressão de vapor, com 5 a 6 anéis aromáticos.

\section{Determinação de hidrocarbonetos em amostras de água dos postos de combustível}

Não foram detectados hidrocarbonetos mono e policíclicos aromáticos em 6 das 45 amostras de água coletadas (Tabela 1S, material suplementar) dos poços de monitoramento. Nas amostras analisadas foram detectados no mínimo 5 e no máximo 13 dos 17 hidrocarbonetos estudados em 39 amostras $(86,7 \%)$ de 14 postos de revenda de combustíveis.

A Figura 3 apresenta os cromatogramas dos íons de quantificação de BTEX obtidos em análise por GC-MS/MS representativos de amostra e de solução padrão.

Benzeno foi a substância predominante entre os poluentes analisados, foi detectado em 39 amostras, sendo quantificado em 11 delas (7 postos de combustíveis; $50 \%$ ). Sua concentração variou entre $<$ LQ e $50 \mathrm{mg} \mathrm{L}^{-1}$. Em todas as amostras onde o benzeno foi quantificado sua concentração encontrou-se muito acima do valor máximo permitido (VMP) para água destinada ao consumo humano, que é de $5 \mu \mathrm{g} \mathrm{L}^{-1}$ (Resolução n ${ }^{\circ}$ 396/08 do CONAMA e Portaria $n^{\circ}$ 2914/2011 do Ministério da Saúde). ${ }^{5,6}$

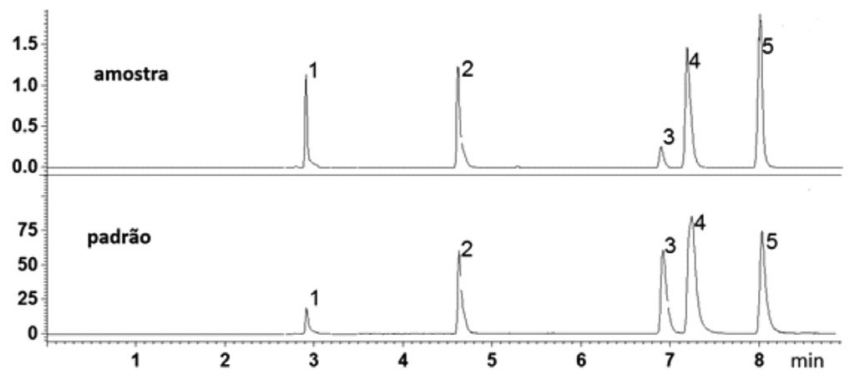

Figura 3. Cromatograma de íons de quantificação de BTEX para amostra e solução padrão contendo $4 \mu \mathrm{g} L^{-1}$ de benzeno (1), tolueno (2), etilbenzeno (3), m,p-xileno (4) e o-xileno (5)

Tolueno e xilenos foram quantificados em 8 amostras (19\%) de seis postos de combustíveis. As concentrações de xilenos totais apresentaram-se acima do VMP em 7 amostras e 4 mostraram altos valores de tolueno. Etilbenzeno foi quantificado em 6 amostras de 6 postos de combustíveis e 3 delas apresentaram valores superiores ao VMP. As concentrações mínimas e máximas encontradas para eles foram: tolueno: $2,4 \times 10^{1}$ e $5,5 \times 10^{3} \mu \mathrm{g} \mathrm{L}{ }^{-1}$, etilbenzeno: $4,3 \times 10^{1}$ e $1,4 \times 10^{4} \mu \mathrm{g} \mathrm{L}^{-1}$; $m$, $p$-xileno: $1,6 \times 10^{1}$ e $20 \times 10^{4} \mu \mathrm{g} \mathrm{L}^{-1}$; $o$-xileno: $7,0 \times 10^{1}$ e $22 \times 10^{4} \mathrm{mg} \mathrm{L}^{-1}$.

A gasolina tipo $\mathrm{C}$ comercializada no Brasil contém em média as seguintes percentagens em volume de BTEX: 0,4\% de benzeno, 2,0\% de tolueno, $0,8 \%$ de etilbenzeno, $0,8 \%$ de $o$-xileno, 2, $0 \% \mathrm{~m}$-xileno e $0,7 \%$ de $p$-xileno. ${ }^{31}$ As mais elevadas concentrações de BTEX na gasolina são para xilenos e tolueno, com valor de aproximadamente 1,7 para a razão xilenos/tolueno. No entanto, observaram-se na maioria das amostras $(n=5)$ razões superiores, entre 6,3 e 7,7. A solubilidade em água do tolueno é superior a dos xilenos quando puros (tolueno: $535 \mathrm{mg} \mathrm{L}^{-1}$, xilenos entre 162 e $178 \mathrm{mg} \mathrm{L}^{-1}$ ) e a pressão de vapor do tolueno é superior (mais volátil) a dos xilenos (pressão de vapor: tolueno: $3,7 \times 10^{-2} \mathrm{~atm}$; xilenos: $\left.1,08 \times 10^{-3}-8,61 \times 10^{-3} \mathrm{~atm}\right) .{ }^{32}$ Os valores obtidos para as razões nas amostras de águas subterrâneas sugerem que a volatilização no solo foi o fator predominante na diferenciação das concentrações que atingiu o lençol d'água. A quantidade de etanol presente na gasolina pode alterar a volatilização dos BTEX de forma diferenciada, dependendo da polaridade ou momento dipolo da substância. ${ }^{33}$ Além disso, outros fatores como degradação microbiológica, foto-decomposição, dispersão vertical e granulometria das partículas do solo e/ou efeitos de interação líquido/estrutura do solo podem interferir na volatilidade dos hidrocarbonetos de solos contaminados por derrame da mistura gasolina/etanol.

O naftaleno foi o HPA mais presente nas amostras, ele foi detectado em 29 e quantificado em 8 com o valor mínimo de $1,0 \times 10^{-1} \mu \mathrm{g} \mathrm{L}^{-1}$ e máximo de $8,5 \mu \mathrm{g} \mathrm{L}^{-1}$. Ind, DBahA e BghiP não foram detectados em nenhuma amostra e em apenas uma foram quantificados $\mathrm{BaA}$, Cri, BbF e BkF em concentração de $8,5 \times 10^{-2}$ e $7,1 \times 10^{-2} \mu \mathrm{g} \mathrm{L}^{-1}$. Os HPA foram quantificados em 7 amostras, em uma apenas naftaleno, nas demais entre 5 e 8 HPA por amostras, sendo estas as mesmas onde foram encontradas as mais elevadas concentrações de BTEX. Nenhum HPA foi encontrado acima do valor máximo permitido.

Com relação ao combustível gasolina tipo C, estudo realizado por Ré-Poppi e colaboradores revelou um valor médio de 15,8\% $(v / v)$ para a concentração de aromático em gasolinas comercializadas em Campo Grande (mínimo: 12 e máximo19 \%). ${ }^{31}$ Neste grupo os hidrocarbonetos monoaromáticos são mais significativos. O maior percentual é para a soma de BTEX, entre 6,8-10 \%. Para a soma de monoaromáticos que não foram investigados neste estudo, como por exemplo, isopropilbenzeno, n-propilbenzeno, 1-metil,3-etil-benzeno, 1-metil, 4 etilbenzeno, 1,3,5 trimetilbenzeno, 1-metil, 2-etilbenzeno e outros o valor é de $5 \%(v / v)$. Naftaleno é o hidrocarboneto poliaromático na composição da gasolina mais significativo entre essa classe de substâncias, com teor em torno de $0,3 \%$, o que parece justificar os resultados obtidos neste estudo.

A soma das concentrações de HPA nas amostras apresentou valor mínimo de $1,0 \times 10^{-1}$ e máximo de $8,7 \mu \mathrm{g} \mathrm{L}^{-1}$. Para a soma de mono aromático nas amostras o valor mínimo foi de $4,1 \times 10^{2} \mu \mathrm{g} \mathrm{L}^{-1}$ e o máximo de $7,4 \times 10^{4} \mu \mathrm{g} \mathrm{L^{-1 }}$. Devido à menor solubilidade dos poliaromáticos e menor concentração nos combustíveis, eram esperadas as baixas concentrações para HPA nas amostras analisadas.

Pode-se observar com base nos resultados que as amostras que apresentaram altas concentrações de BTEX pertencem a poços pouco profundos (3 e 8,5 m).

Para a análise de agrupamento hierárquico foram consideradas as amostras que revelaram a presença de BTEX e/ou HPA, amostras de número 1 a 39 (Tabela 1S, material suplementar). A Figura 4 mostra o dendrograma relativo à similaridade das amostras.

As amostras se agruparam formando 7 grupos a um nível de similaridade de $85 \%$. O segundo cluster foi formado por 33 amostras de águas provenientes de 14 postos de revenda de combustível. Neste 


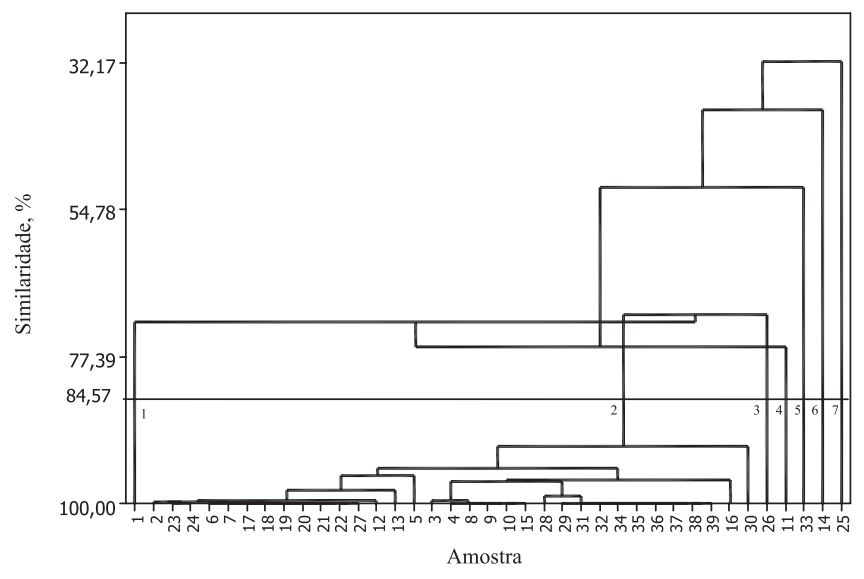

Figura 4. Dendrograma evidenciando a similaridade entre amostras

grande grupo ficaram as amostras que não se detectou a HPA e as que mostraram concentração de HPA inferior ao LQ e concentração de BTEX entre LQ e 7,8x10 $\mathrm{ug} \mathrm{L}^{-1}$ (amostra 5).

Este grupo se subdividiu em dois subgrupos: 1.a e 1.b, este ultimo formado pela amostra 30 de um poço de 3,9 $\mathrm{m}$ de profundidade que apresentou elevada concentração para benzeno $\left(15,9 \mu \mathrm{g} \mathrm{L}^{-1}\right) \mathrm{e}$ traços para todas as outras substâncias analisadas. O subgrupo 1.a subdividiu-se formando mais dois subgrupos 1.a1 e 1.a2. Estes se subdividiram em vários outros. As maiores similaridades foram encontradas entre as amostras que formaram esses pequenos subgrupos, entre 92,9 e $100 \%$.

As amostras de número 1, 26, 11, 33, 14 e 25 formaram clusters individuais e se caracterizaram por apresentar elevados valores de concentração para BTEX e valores variando entre 1,0 e $8,7 \mu \mathrm{g} \mathrm{L}^{-1}$ para o total de HPA. A amostra 11 (cluster 4 ) proveniente de um poço com 6,5 m de profundidade apresentou concentração total de BTEX de 8,3 x $10^{3} \mu \mathrm{g} \mathrm{L} \mathrm{L}^{-1}$ e $8,7 \mu \mathrm{g} \mathrm{L}^{-1}$ para HPA sendo o maior valor encontrado para a soma das concentrações de naftaleno, acenaftileno, acenafteno, fluoreno e fenantreno. O cluster 3 foi formado pela amostra 1, poço com 6,3 m de profundidade, que apresentou 2,8 x $10^{3} \mu \mathrm{g} \mathrm{L} \mathrm{L}^{-1} \mathrm{de}$ BTEX e 4,7 $\mu \mathrm{g} \mathrm{L}^{-1}$ de HPA. As amostras 26 e 33 (poços com 8,4 e 5,5 m de profundidade) formaram os clusters 3 e 5 . A concentração total de BTEX foi de $2,6 \times 10^{4} \mu \mathrm{g} \mathrm{L}^{-1}$ na amostra 26 e de $5,3 \times 10^{4} \mu \mathrm{g} \mathrm{L} \mathrm{L}^{-1}$ na amostra 33, enquanto que, para a soma das concentrações de HPA encontrou-se $1,0 \mu \mathrm{g} \mathrm{L}^{-1}$ na amostra $26 \mathrm{e} 1,9 \mu \mathrm{g} \mathrm{L} \mathrm{L}^{-1}$ na amostra 33. A concentração de BTEX de $7,4 \times 10^{4} \mu \mathrm{g} \mathrm{L}^{-1}$, a mais alta encontrada, foi da amostra 14 (cluster 6 ) proveniente de um poço de $6,9 \mathrm{~m}$. Nesta amostra a concentração total de HPA foi de $2,5 \mu \mathrm{g} \mathrm{L^{-1 }}$. O cluster 7 foi formado pela amostra 25 que apresentou o segundo maior valor de concentração de $\operatorname{BTEX}\left(6,0 \times 10^{4} \mu \mathrm{g} \mathrm{L}^{-1}\right)$ e de $\operatorname{HPA}\left(8,5 \mu \mathrm{g} \mathrm{L}^{-1}\right)$.

\section{CONCLUSÃO}

Os métodos de análise usando a HS-SPME/GC-MS/MS apresentaram sensibilidade, linearidade, precisão e exatidão adequadas e foram aplicados nas análises de águas de postos de revenda de combustíveis para determinação de BTEX e HPA.

Os resultados revelaram concentração de benzeno superior ao VMP $\left(5 \mu \mathrm{g} \mathrm{L}^{-1}\right)$ em 11 poços de água com profundidade entre 3,0 e $8,4 \mathrm{~m}$, situados em 7 postos de comercialização de combustíveis. As concentrações de benzeno variaram entre $409 \mu \mathrm{g} \mathrm{L}^{-1}$ a 50 x $10^{3} \mu \mathrm{g} \mathrm{L} \mathrm{L}^{-1}$. Dentre estes poços, detectou-se também valores de concentrações acima do VPM em 7 poços para xilenos, 4 para tolueno e 3 para etilbenzeno.

Dentre os 16 HPA analisados, o naftaleno foi encontrado em níveis superiores aos demais, sua concentração variou de $1,0 \times 10^{-1}$ $\mu \mathrm{g} \mathrm{L} \mathrm{L}^{-1}$ a $8,5 \mu \mathrm{g} \mathrm{L}^{-1}$ e a soma das concentrações dos HPA ficou entre
0,1 e $8,7 \mu \mathrm{g} \mathrm{L}^{-1}$. Os valores 6,3 a 7,7 obtidos para as razões entre as concentrações de xilenos/tolueno nas amostras quando comparado ao valor de 1,7 em gasolinas do tipo $\mathrm{C}$ sugerem maior volatilização de tolueno no solo.

Os resultados apresentados neste trabalho mostraram níveis preocupantes de BTEX em água subterrânea de 50\% dos postos de revenda de combustível amostrados. Essas informações fornecem um quadro parcial da qualidade da água subterrânea da Região Central do município de Campo Grande. Estudos ainda devem ser realizados abrangendo uma maior amostragem da região Central e outras regiões do município.

\section{MATERIAL SUPLEMENTAR}

Está disponível em http://quimicanova.sbq.org.br, em arquivo PDF, com acesso livre. A Tabela $1 \mathrm{~S}$ contém os valores de concentração de BTEX e HPA encontrados nas amostras de água subterrânea de postos de revenda de combustíveis.

\section{AGRADECIMENTOS}

Os autores agradecem ao apoio financeiro fornecido pela FUNDECT, CAPES, CNPq e PROPP-UFMS.

\section{REFERÊNCIAS}

1. http://www.anp.gov.br/?pg=61476\&m=número, acessada em Fevereiro 2013.

2. Mimdrisz, A. C.; Tese de Doutorado, Instituto de Pesquisas Energéticas e Nucleares, Autarquia Associada à Universidade de São Paulo, Brasil, 2006.

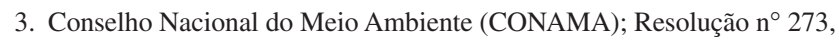
Brasil, 2000.

4. Oliveira, P. T. S.; Ayres, F. M.; Peixoto Filho, G. E. C.; Martins, I. P.; Sociedade \& Natureza 2008, $20,87$.

5. Conselho Nacional do Meio Ambiente (CONAMA); Resolução n 396, Brasil, 2008.

6. Brasil; Portaria n 2914, Ministério da Saúde: Brasília, Brasil 2011.

7. Heleno, F. F.; Lima, A. C.; Afonso, R. J. C. F.; Coutrim, M. X.; Quim. Nova 2010, 33, 329.

8. Menéndez, J. C. F.; Sánchez, M. L. F.; Uria, J. E. S.; Martínez, E. F.; Sanz-Medel, A.; Anal. Chim. Acta 2000, 415, 9.

9. MacGillivray, B.; Pawliszyn, J.; Fowlie, P.; Sagara, C.; J. Chromatogr. Sci. 1994, 32, 317.

10. Dórea, H. S.; Bispo, J. R. L.; Aragão, K. A. S.; Cunha, B. B.; Navickiene, S.; Alves, J. P. H.; Romão, L. P. C.; Garcia, C. A. B.; Microchem. J. 2007, 85, 234.

11. Aguilera-Herrador, E.; Lucena, R.; Cárdenas, S.; Valcárcel, M.; J. Chromatogr. A 2008, 1201, 106.

12. Sarafraz-Yazdi, A.; Amiri, A. H.; Es'haghi, Z.; Talanta 2009, 78, 936.

13. Sarafraz-Yazdi, A.; Amiri, A. H.; Es'haghi, Z.; Chemosphere 2008, 71, 671.

14. Ma, X.; Huang, M.; Li, Z.; Wu, J.; J. Hazard. Mater. 2011, 194, 24.

15. Ouyanga, G.; Zhaob, W.; Pawliszyn, J.; J. Chromatogr. A 2007, 1138, 47.

16. Kim, H.; Kim, S.; Lee, S.; Talanta 2012, 97, 432.

17. Arambarri, I.; Lasa, M.; Garcia, R.; Millán, E.; J. Chromatogr. A 2004, 1033, 193.

18. Environmental Protection Agency; methods 524.2, 1995

19. Law, R. J.; Dawes, V. J.; Woodhead, R. J.; Matthiessen, P.; Mar. Pollut. Bull. 1997, 34, 306.

20. Song, X.; Li, J.; Xu, S.; Ying, R.; Ma, J.; Liao, C.; Liu, D.; Yu, J.; Lingxin Chen, L.; Talanta 2012, 99, 82. 
21. Oliferova, L.; Statkus, M.; Tsysin, G.; Shpigun, O.; Zolotov, Y.; Anal. Chim. Acta 2005, 538, 35.

22. Michor, G.; Carron, J.; Bruce, S.; Cancill, D. A.; J. Chromatogr. A 1996, $732,85$.

23. García-Falcón, M. S.; Cancho-Grande, B.; Simal-Gándara, J.; Water Research 2004, 38, 1679.

24. Kolahgar, B.; Hoffmann, A.; Heiden, A. C.; J. Chromatogr. A 2002, 963 , 225.

25. Prieto, A.; Telleria, O.; Etxebarria, N.; Fernández, L. A.; Usobiaga, A.; Zuloaga, O.; J. Chromatogr. A 2008, 1214, 1.

26. Rodil, R.; Schellin, M.; Popp, P.; J. Chromatogr. A 2007, 1163, 288.

27. Coelho, E.; Ferreira, C.; Almeida, C. M. M.; J. Braz. Chem. Soc. 2008, 19, 1084.
28. Rianawati, E.; Balasubramanian, R.; Phys. Chem. Earth 2009, 34, 857.

29. Chaves, A. R.; Queiroz, M. E. C.; Quim. Nova 2008, 31, 1814.

30. Bianchin, J. N.; Nardini, G.; Merib, J.; Dias, A. N.; Martendal, E.; Carasek, E.; J. Chromatogr. A 2012, 1233, 22.

31. Ré-Poppi, N.; Almeida, F. F. P.; Cardoso, C. A. L.; Raposo Jr., J. L.; Viana, L. H.; Silva, T. Q.; Souza, J. L.C.; Ferreira, V. S.; Fuel 2009, 88, 418.

32. Lide, D. R.; Handbook of Chemistry and Physics. $76^{\text {th }}$ ed., CRC Press: Florida, 1996.

33. Finotti, A. R.; Teixeira, C. E.; Fedrezzi, F.; Calgliari, J.; Nascimento Filho, I.; Eng. Sanit. Ambient. 2009, 14, 443. 


\section{MÉTODOS PARA ANÁLISES DE HPA E BTEX EM ÁGUAS SUBTERRÂNEAS DE POSTOS DE REVENDA DE COMBUSTÍVEIS: UM ESTUDO DE CASO EM CAMPO GRANDE, MS, BRASIL}

Sâmya Soler Gebara, Nilva Ré-Poppi* e André Luiz Carneiro Soares do Nascimento

Departamento de Química, Universidade Federal de Mato Grosso de Sul, 79080-190 Campo Grande - MS, Brasil Jorge Luiz Raposo Junior

Faculdade de Ciências Exatas e Tecnologia, Universidade Federal da Grande Dourados, 79804-970 Dourados - MS, Brasil

Tabela 1S. Valores médios de concentração obtidos para BTEX e HPA nas amostras de água analisadas

\begin{tabular}{|c|c|c|c|c|c|c|c|c|c|c|c|c|c|c|c|c|}
\hline \multirow{2}{*}{$\mathrm{N}^{\circ}$} & \multirow{2}{*}{$\begin{array}{c}\text { Prof. } \\
\text { (m) }\end{array}$} & \multicolumn{15}{|c|}{ Concentração das substâncias em $\mu \mathrm{g} \mathrm{L}{ }^{-1}$} \\
\hline & & Ben & Tol & Etilben & $m, p$-xil & $o$-xil & $\mathrm{Naf}$ & Aci & Ace & Flu & Fen & Ant & Flt & Pir & $\mathrm{BaA}+\mathrm{Cri}$ & $\mathrm{BbF}+\mathrm{BkF}$ \\
\hline 1 & 6,3 & $2,5 \times 10^{3}$ & $3,9 \times 10^{1}$ & $<$ & $1,4 \times 10^{2}$ & $1,7 \times 10^{2}$ & 3,7 & $1,0 \times 10^{-1}$ & $1,0 \times 10^{-1}$ & $3,0 \times 10^{-1}$ & $5,0 \times 10^{-1}$ & $<$ & nd & nd & nd & nd \\
\hline 2 & 7,1 & $<$ & $<$ & $<$ & $<$ & $<$ & $<$ & $<$ & $<$ & nd & nd & nd & nd & nd & nd & nd \\
\hline 3 & 6,8 & $4,1 \times 10^{2}$ & $<$ & $<$ & $<$ & $<$ & $1,0 \times 10^{-1}$ & $<$ & $<$ & $<$ & $<$ & $<$ & $<$ & $<$ & nd & nd \\
\hline 4 & 15,5 & $<$ & $<$ & $<$ & $<$ & $<$ & $<$ & $<$ & $<$ & $<$ & $<$ & $<$ & $<$ & $<$ & nd & nd \\
\hline 5 & 7,0 & $5,8 \times 10^{3}$ & $2,6 \times 10^{2}$ & $4,3 \times 10^{1}$ & $1,1 \times 10^{3}$ & $6,3 \times 10^{2}$ & nd & nd & nd & nd & nd & nd & nd & nd & nd & nd \\
\hline 6 & 10,0 & $<$ & $<$ & $<$ & $<$ & $<$ & nd & nd & nd & nd & nd & nd & nd & nd & nd & nd \\
\hline 7 & 8,5 & $<$ & $<$ & $<$ & $<$ & $<$ & nd & nd & nd & nd & nd & nd & nd & nd & nd & nd \\
\hline 8 & 6,8 & $<$ & $<$ & $<$ & $<$ & $<$ & $<$ & $<$ & $<$ & $<$ & $<$ & $<$ & $<$ & $<$ & nd & nd \\
\hline 9 & 7,0 & $<$ & $<$ & $<$ & $<$ & $<$ & $<$ & $<$ & $<$ & $<$ & $<$ & $<$ & $<$ & $<$ & nd & nd \\
\hline 10 & 31,0 & $<$ & $<$ & $<$ & $<$ & $<$ & $<$ & $<$ & $<$ & $<$ & $<$ & $<$ & $<$ & $<$ & nd & nd \\
\hline 11 & 6,5 & $1,7 \times 10^{3}$ & $5,8 \times 10^{2}$ & $2,4 \times 10^{3}$ & $1,9 \times 10^{3}$ & $1,7 \times 10^{3}$ & 8,5 & $2,8 \times 10^{-2}$ & $7,8 \times 10^{-2}$ & $3,8 \times 10^{-2}$ & $3,4 \times 10^{-2}$ & nd & nd & nd & nd & nd \\
\hline 12 & 6,9 & $<$ & $<$ & $<$ & $<$ & $<$ & $<$ & $<$ & $<$ & $<$ & $<$ & nd & nd & nd & nd & nd \\
\hline 13 & 7,0 & $<$ & $<$ & $<$ & $<$ & $<$ & $<$ & $<$ & $<$ & $<$ & $<$ & nd & nd & nd & nd & nd \\
\hline 14 & 6,9 & $1,8 \times 10^{4}$ & $5,5 \times 10^{3}$ & $1,4 \times 10^{4}$ & $1,5 \times 10^{4}$ & $2,2 \times 10^{4}$ & 1,7 & $5,9 \times 10^{-2}$ & $8,9 \times 10^{-2}$ & $7,5 \times 10^{-2}$ & $4,0 \times 10^{-1}$ & $1,0 \times 10^{-1}$ & $<$ & $5,6 \times 10^{-2}$ & nd & nd \\
\hline 15 & 8,0 & $<$ & $<$ & $<$ & $<$ & $<$ & $<$ & $<$ & $<$ & $<$ & $<$ & $<$ & $<$ & $<$ & nd & nd \\
\hline 16 & 7,9 & $1,1 \times 10^{3}$ & $3,1 \times 10^{1}$ & $<$ & $1,6 \times 10^{1}$ & $2,4 \times 10^{3}$ & $<$ & $<$ & $<$ & $<$ & $<$ & $<$ & $<$ & $<$ & nd & nd \\
\hline 17 & 7,5 & $<$ & $<$ & $<$ & $<$ & $<$ & nd & nd & nd & nd & nd & nd & nd & nd & nd & nd \\
\hline 18 & 7,0 & $<$ & $<$ & $<$ & $<$ & $<$ & nd & nd & nd & nd & nd & nd & nd & nd & nd & nd \\
\hline 19 & 8,2 & $<$ & $<$ & $<$ & $<$ & $<$ & nd & nd & nd & nd & nd & nd & nd & nd & nd & nd \\
\hline 20 & 8,4 & $<$ & $<$ & $<$ & $<$ & $<$ & nd & nd & nd & nd & nd & nd & nd & nd & nd & nd \\
\hline 21 & 9,5 & $<$ & $<$ & $<$ & $<$ & $<$ & nd & nd & nd & nd & nd & nd & nd & nd & nd & nd \\
\hline 22 & 9,0 & $<$ & $<$ & $<$ & $<$ & $<$ & nd & nd & nd & nd & nd & nd & nd & nd & nd & nd \\
\hline 23 & 8,2 & $<$ & $<$ & $<$ & $<$ & $<$ & $<$ & $<$ & $<$ & $<$ & nd & nd & nd & nd & nd & nd \\
\hline 24 & 7,8 & $<$ & $<$ & $<$ & $<$ & $<$ & $<$ & $<$ & $<$ & $<$ & nd & nd & nd & nd & nd & nd \\
\hline 25 & 7,8 & $5,0 \times 10^{4}$ & $3,0 \times 10^{3}$ & $1,5 \times 10^{3}$ & $2,7 \times 10^{3}$ & $3,2 \times 10^{3}$ & 4,0 & 3,0 & $4,0 \times 10^{-1}$ & $7,0 \times 10^{-1}$ & $5,7 \times 10^{-3}$ & $1,0 \times 10^{-1}$ & $2,9 \times 10^{-2}$ & $3,0 \times 10^{-1}$ & nd & nd \\
\hline 26 & 8,4 & $1,4 \times 10^{3}$ & $4,9 \times 10^{1}$ & $1,0 \times 10^{2}$ & $2,0 \times 10^{4}$ & $4,4 \times 10^{3}$ & $7 \times 10^{-1}$ & $4,9 \times 10^{-2}$ & $3,1 \times 10^{-2}$ & $1,0 \times 10^{-1}$ & $1,2 \times 10^{-1}$ & $<$ & $<$ & $<$ & nd & nd \\
\hline 27 & 8,5 & $<$ & $<$ & $<$ & $<$ & $<$ & nd & nd & nd & nd & nd & nd & nd & nd & nd & nd \\
\hline 28 & 3,0 & $1,7 \times 10^{3}$ & $<$ & $<$ & $<$ & $<$ & $<$ & $<$ & $<$ & $<$ & $<$ & $<$ & $<$ & $<$ & $<$ & $<$ \\
\hline 29 & 4,3 & $<$ & $<$ & $<$ & $<$ & $<$ & $<$ & $<$ & $<$ & $<$ & $<$ & $<$ & $<$ & $<$ & $<$ & $<$ \\
\hline 30 & 3,9 & $1,6 \times 10^{4}$ & $<$ & $<$ & $<$ & $<$ & $<$ & $<$ & $<$ & $<$ & $<$ & $<$ & $<$ & $<$ & $<$ & $<$ \\
\hline
\end{tabular}

*e-mail: ni_ufms@hotmail.com 
Tabela 1S. continuação

\begin{tabular}{|c|c|c|c|c|c|c|c|c|c|c|c|c|c|c|c|c|}
\hline \multirow{2}{*}{$\mathrm{N}^{\circ}$} & \multirow{2}{*}{$\begin{array}{c}\text { Prof. } \\
\text { (m) }\end{array}$} & \multicolumn{15}{|c|}{ Concentração das substâncias em $\mu \mathrm{g} \mathrm{L} \mathrm{L}^{-1}$} \\
\hline & & Ben & Tol & Etilben & $m, p$-xil & $o$-xil & $\mathrm{Naf}$ & Aci & Ace & Flu & Fen & Ant & Flt & Pir & $\mathrm{BaA}+\mathrm{Cri}$ & $\mathrm{BbF}+\mathrm{BkF}$ \\
\hline 31 & 5,0 & $<$ & $<$ & $<$ & $<$ & $<$ & $<$ & $<$ & $<$ & $<$ & $<$ & $<$ & $<$ & $<$ & $<$ & $<$ \\
\hline 32 & 4,5 & $<$ & $<$ & $<$ & $<$ & $<$ & $<$ & $<$ & $<$ & $<$ & $<$ & $<$ & $<$ & $<$ & $<$ & $<$ \\
\hline 33 & 5,5 & $5,0 \times 10^{3}$ & $2,4 \times 10^{1}$ & $6,8 \times 10^{1}$ & $1,1 \times 10^{2}$ & $7,0 \times 10^{1}$ & 1,0 & $2,0 \times 10^{-1}$ & $<$ & $6,5 \times 10^{-2}$ & $4 \times 10^{-1}$ & $2,5 \times 10^{-2}$ & $<$ & $3,7 \times 10^{-2}$ & $8,5 \times 10^{-2}$ & $7,1 \times 10^{-2}$ \\
\hline 34 & 16,0 & $<$ & $<$ & $<$ & $<$ & $<$ & $<$ & $<$ & $<$ & $<$ & $<$ & $<$ & $<$ & $<$ & $<$ & $<$ \\
\hline 35 & 15,8 & $<$ & $<$ & $<$ & $<$ & $<$ & $<$ & $<$ & $<$ & $<$ & $<$ & $<$ & $<$ & $<$ & $<$ & $<$ \\
\hline 36 & 15,0 & $<$ & $<$ & $<$ & $<$ & $<$ & $<$ & $<$ & $<$ & $<$ & $<$ & $<$ & $<$ & $<$ & $<$ & $<$ \\
\hline 37 & 8,5 & $<$ & $<$ & $<$ & $<$ & $<$ & $<$ & $<$ & $<$ & $<$ & $<$ & $<$ & $<$ & $<$ & $<$ & $<$ \\
\hline 38 & 6,0 & $<$ & $<$ & $<$ & $<$ & $<$ & $<$ & $<$ & $<$ & $<$ & $<$ & $<$ & $<$ & $<$ & $<$ & $<$ \\
\hline 39 & 7,5 & $<$ & $<$ & $<$ & $<$ & $<$ & $<$ & $<$ & $<$ & $<$ & $<$ & $<$ & $<$ & $<$ & $<$ & $<$ \\
\hline 40 & 31,5 & nd & nd & nd & nd & nd & nd & nd & nd & nd & nd & nd & nd & nd & nd & nd \\
\hline 41 & 16,0 & nd & nd & nd & nd & nd & nd & nd & nd & nd & nd & nd & nd & nd & nd & nd \\
\hline 42 & 27,3 & nd & nd & nd & nd & nd & nd & nd & nd & nd & nd & nd & nd & nd & nd & nd \\
\hline 43 & 20,0 & nd & nd & nd & nd & nd & nd & nd & nd & nd & nd & nd & nd & nd & nd & nd \\
\hline 44 & 21,0 & nd & nd & nd & nd & nd & nd & nd & nd & nd & nd & nd & nd & nd & nd & nd \\
\hline 45 & 19,0 & nd & nd & nd & nd & nd & nd & $\mathrm{Nd}$ & nd & nd & nd & nd & nd & nd & nd & nd \\
\hline
\end{tabular}

Prof.: profundidade do poço; nd: não detectado; < detectado em concentração abaixo do limite de quantificação. 